\title{
Comparison of blood clam (anadara granosa) shell paste, shrimp (litopenaeus vannamei) shell paste and casein phosphopeptide-amorphus calcium phosphate (CPP-ACP) paste as teeth remineralization material
}

\author{
Asmawati, ${ }^{1 *}$ Bahruddin Thalib, ${ }^{2}$ Alqarama M. Thalib, ${ }^{3}$ Delvi S. Reni, ${ }^{2}$ Rafikah Hasyim ${ }^{1}$
}

\section{Abstract}

Objective: The aim of this study was to determine the comparison of blood clam (anadara granosa) shell paste, shrimp (litopenaeus vannamei) shell paste and casein phosphopeptideamorphus calcium phosphate (CPP-ACP) paste as teeth remineralization material.

Material and Methods: This study was an experimental laboratory with cross sectional design. Study sample was 15 maxillary central incisors that were applied with 35\% hydrogen peroxide for 2 hours, then assessed with Energy Dispersive Spectroscopy (EDS). Samples were divided into 3 groups: 5 samples were applied using blood clam (anadara granosa) shell paste, 5 samples using shrimp shell paste and 5 samples were applied using CPP-ACP paste every 8 hours for 14 consecutive days then checked with EDS. Data analysis using SPSS test independent t-test to see comparison of blood clam (anadara granosa) shell paste, shrimp (litopenaeus vannamei) shell paste and casein phosphopeptide-amorphus calcium phosphate (CPP-ACP) paste as teeth remineralization material.

Results: The result of this study showed $\mathrm{P}>0.05$ which means there was no significant difference between blood clam shell paste, shrimp shell paste and CPP-ACP mineral composition.

Conclusion: Blood clam shell paste and shrimp shell paste has an effective value to be used as tooth remineralization material.
${ }^{1}$ Department of Oral Biology, Faculty of Dentistry, Hasanuddin University, Makassar, Indonesia ${ }^{2}$ Department of Prosthodontics, Faculty of Dentistry, Hasanuddin University, Makassar, Indonesia ${ }^{3}$ Department of Oral and Dental Hospital, Hasanuddin University, Makassar, Indonesia
*Corresponding to: Asmawati, Department of Oral Biology, Faculty of Dentistry, Hasanuddin University, Makassar, Indonesia asmaamin281068@gmail.com

Received: 5 November 2018 Revised: 20 November 2018 Accepted: 7 November 2018 Available Online 1 December 2018

Keywords: Blood clam shell paste, Shrimp shell paste, CPP-ACP paste, Tooth remineralization

Cite this Article: Asmawati, Thalib B, Thalib AM, Reni DS, Hasyim R. 2018. Comparison of blood clam (anadara granosa) shell paste, shrimp (litopenaeus vannamei) shell paste and casein phosphopeptide-amorphus calcium phosphate (CPP-ACP) paste as teeth remineralization material. Journal of Dentomaxillofacial Science 3(3): 162-165. D0I: 10.15562/jdmfs.v3i3.834

\section{Introduction}

Indonesia is a country that has a wider territorial waters of the mainland, one of which is the largest producer of blood clam and shrimp in the world. Some of the most popular clam species in Indonesia are blood clams (Anadara granosa) and shrimp (Litopenaeus vannamei). The use of blood clam is usually only consumed for the meat while the shell is widely used for handicrafts such as wall hangings, or for mixed fodder otherwise it just becomes waste and much thrown away. Shell waste contains high calcium carbonate which is $98 \%$ potential to be utilized as well as shrimp that every year is produced and processed as much as 1500 ton and $75 \%$ from total weight of shrimp is the waste in the form of shells, shrimp heads and other waste that have not been utilized optimally, whereas shrimp shell contains chitosan that is very useful..$^{1-3}$

Calcium carbonate that is widely found in blood clams shell is the main inorganic component of bone and tooth formation thus this material is one of active ingredients to be a protection against demineralization, as well as calcium in the shrimp shell that can be processed into nanocalcium to be absorbed quickly to provide some benefits to health as well as become bone and tooth replacement material because it is biocompatible, biodegradable, bioresorbable, and non-toxic, also can improve wound healing, as antimicrobial, anti cholesterol. ${ }^{4}$ Both of the above materials can be used as tooth remineralization materials.

There has been many substances produced to induce enamel remineralization besides fluor, such as casein phosphopeptide stabilizes amorphous calcium phosphate (CPP-ACP) unstabilized amorphous calcium phosphate and bioactive glass containing calcium sodium phosphosilicate, the material has a high calcium and phosphate composition to strengthens dental enamel..$^{5}$ For that reason, the authors are interested to examine the comparison of blood clams shell paste, shrimp shell paste and CCP-ACP paste.

\section{Material and Methods Preparation of blood clam paste}

Blood clam shells that have been removed then washed with clean water and boiled for \pm 1 hour with temperature $100^{\circ} \mathrm{C}$. After cooling down, the 
shells are washed and dried in the sun, rinsed again with aquades and dried in an oven at $80^{\circ} \mathrm{C}$ for 24 hours. Next, the shells were crushed using mortar and pestle, and mashed using a blender. Fine powder shells then sifted, and calcined at $1000^{\circ} \mathrm{C}$ for 5 hours to convert $\mathrm{CaCO} 3$ to $\mathrm{CaO}$. Furthermore, $100 \mathrm{ml}$ of (NH4)2HPO4 $0.3 \mathrm{M}$ solution was put drop by drop into the $\mathrm{CaO}$ suspension at $40^{\circ} \mathrm{C}$ while stirring and allowed to stand for 24 hours at room temperature. The precipitate formed is filtered using Whatman filter paper no 42 then dried at $110^{\circ} \mathrm{C}$ for 5 hours.

Aquades $25 \mathrm{ml}$ is boiled and dissolve methylparaben and saccharin. Dispersed CMC (Carboxy Methyl Cellulose) at $70^{\circ} \mathrm{C}$ to form gel. Then

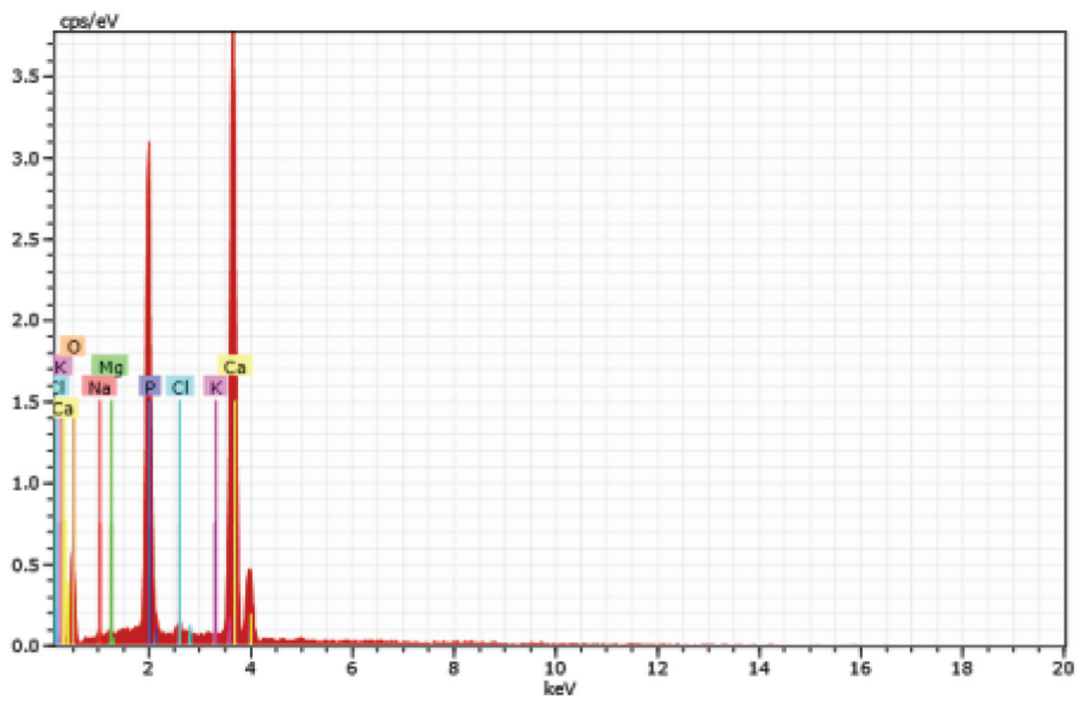

Figure 1 X-ray diffraction pattern of dental enamel after application of hydrogen peroxida ( $\mathrm{H} 2 \mathrm{O} 2) 35 \%$

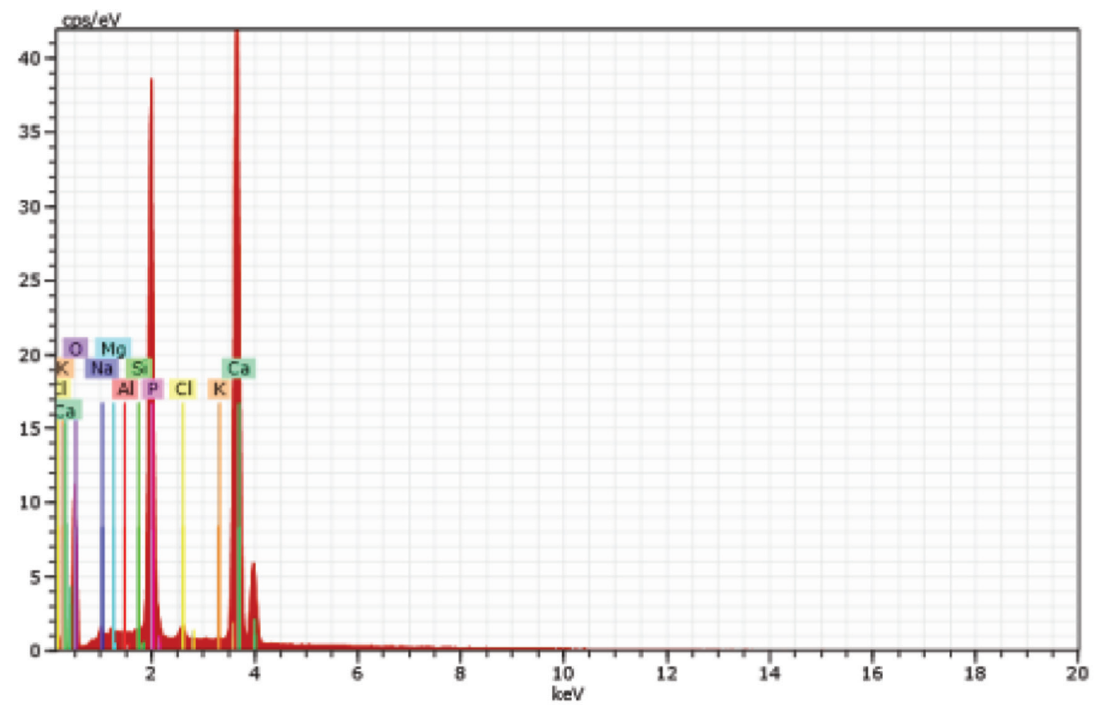

Figure 2 X-ray diffraction pattern of dental enamel after the application of blood clam paste synthesis result of hydroxyapatite shell crushed along with sodium lauryl sulfate and addded with glycerine, sorbitol and CMC gel, consecutively,crushed to form a homogeneous paste.

\section{Preparation of shrimp shell paste}

Shrimp shell as much as 10 grams is cleaned under running water and dried at room temperature, blend using a blender, then sifted and crushed until smooth.

The aquades were heated then added with nipagin and 0.2 gr NaCMC and 10 gr fine shrimp shell then moistened with $1 \mathrm{~g}$ glycerol. Prepare Menthol as much as $0.05 \mathrm{~g}$ mixed with alcohol until dissolved. Add menthol and crushed to form a homogeneous paste.

This study was an experimental laboratory with cross-sectional study design. Data analysis using SPSS Independent T-test to compare the effectivity of blood clam shells (anadara granosa), shrimp shells (litopenaeus vannamei) and casein phosphopeptide-amorphus calcium phosphate (CPP-ACP) as a tooth remineralization material.

The samples of this study were 15 post-extracted maxillary central incisors. The sample was applied with $35 \%$ hydrogen peroxide $(\mathrm{H} 2 \mathrm{O} 2)$ as a demineralization agent for 2 hours. Then the sample is cleaned with aquades then dried. Then examined with Energy Dispersive Spetroscopy (EDS) to see changes in email structure due to the demineralization process. Fifteen samples that have been applied with $\mathrm{H} 2 \mathrm{O} 2$ and checked with EDS were divided into three groups, the first group of 5 samples were applied with blood clams shell paste, the second group with shrimp shell paste then the third group with casein phospopeptides-amorphous calcium phospatase (CPP-ACP) as control. The duration is 8 hours for each agent, for 14 days, then checked with EDS.

\section{Results}

EDS examination results show the amount of mineral composition on the sample after $\mathrm{H} 2 \mathrm{O} 2$ application figure 1, then applied with CPP-ACP paste figure 2 and shrimp shell paste figure 3 and figure 4.

Based on the Independent $t$-test to determine the effectiveness comparison of blood clam (anadara granosa), shrimp shells (Litopenaeus Vannamei) and Casein phosphopeptide-amorphus calcium phosphate (CPP-ACP) as teeth remineralization material. Table 1.

Based on table 1 with Kruskal Wallis t-test, the mean inorganic composition of calcium, sodium, magnesium, aluminum, clorine and potassium from blood clam and shrimp paste have no significant difference with CCP-ACP paste with 




Figure 3 X-ray diffraction pattern of dental enamel after application of casein phospopeptides- Amorphous calsium phospatase (CPP-ACP)



Figure 4 X-ray diffraction pattern of dental enamel after application of shrimp shell paste

$\mathrm{P}>0.05$ except for phosphorus, there was a significant difference with $\mathrm{P}$ value $0.037<0.05$ which means there was a difference of inorganic phosphorus content between blood clam and shrimp paste.

\section{Discussion}

This study has been approved by the ethics committee with the number: 781 / H4.8.45.31 / PP36KOMETIK / 2017. Enamel is the hardest substance on the body and has a high calcification. The main content of enamel consists of inorganic materials and little organic matter. The inorganic enamel content consists of $90-92 \%$ calcium hydroxyapatite and other minerals of 3-5\%.,

Demineralization is the destruction of enamel hydroxyapatite due to increased concentration of hydrogen ions caused by the $\mathrm{pH}$ of the solution around the enamel surface that is lower than 5.5. Demineralization occurs by diffusion, ie the process of transfer of watersoluble molecules or ions to or from the enamel to the saliva because there is a difference in the concentration of acidity on the surface and in the enamel. Continuous demineralization will form small pores or porosity on the enamel surface of the tooth so that it can cause the dissolution of calcium minerals. ${ }^{8}$ Calcium is one of the nutrients that are needed for various functions of the body to support the development of more optimal organ function. Lack of calcium in the body will results in a variety of major complaints on bone, teeth, blood, nerves and body metabolism. ${ }^{9}$

The occurrence of demineralization process can have negative effects such as dental pain, increased risk of dental caries to fracture, for which applications are needed that can stimulate tooth remineralization, which contains calcium, phosphate and fluor.

The main composition of the shrimp vannamei is calcium, which is the main constituent of shrimp shell. Several studies have reported that calcium bioavailability is used for chemical and physiological processes that affect the absorption of calcium in the body so that it can be used by the body to perform its functions. ${ }^{10}$

Another study found that the characterization and bioavaibility of calcium from vannaimai shell of shrimp shells that has been immersed for 48 hours produced calcium levels as much as $85.49 \%$. The main constituent mineral of nanocalcium is calcium, but nanocalcium also contains other mineral components such as magnesium, potassium, sodium, phosphorus, iron, zinc and mangan. ${ }^{11}$

Remineralization is a process in which calcium and phosphate mineral ions re-form hydroxyapatite crystals in enamel. The remineralization process is an important process that has a significant effect on tooth hardness and strength. The presence of materials containing calcium and phosphorus is expected to produce remineralization on teeth. This study proves that blood clam and shrimp shells have a composition similar to CCP-ACP so it is expected that the development of natural material utilization, especially shrimp shells that can be used as a teeth remineralization material.

The statistical test results obtained $\mathrm{P}>0.05$ also proved that there was no significant difference in most of the mineral composition contained in blood clam and shrimp paste compared to CPP-ACP, this means that blood clam and shrimps paste have the effectiveness to be teeth remineralization material. 
Table 1 Mineral composition on dental enamel after blood clam paste, shrimp shell paste, and CPP-ACP application

\begin{tabular}{|c|c|c|c|c|}
\hline Mineral & Group & $\mathbf{N}$ & Mean \pm SD & $P$ value \\
\hline \multirow[t]{3}{*}{ Calcium } & Blood clam & 5 & $39.66 \pm 9.49$ & \\
\hline & Shrimp shell & 5 & $38.18 \pm 1.04$ & 0.141 \\
\hline & CPP-ACP I & 5 & $39.39 \pm 0.60$ & \\
\hline \multirow[t]{3}{*}{ Phosphorus } & Blood clam Shrimp & 5 & $15.99 \pm 3.20$ & \\
\hline & shell & 5 & $18.33 \pm 0.21$ & $0.037^{\star}$ \\
\hline & CPP-ACP I & 5 & $18.29 \pm 0.19$ & \\
\hline \multirow[t]{3}{*}{ Sodium } & Blood clam & 5 & $1.62 \pm 1.97$ & \\
\hline & Shrimp shell & 5 & $1.09 \pm 0.28$ & 0.623 \\
\hline & CPP-ACP I & 5 & $0.92 \pm 0.18$ & \\
\hline \multirow[t]{3}{*}{ Magnesium } & Blood clam & 5 & $0.74 \pm 1.11$ & \\
\hline & Shrimp shell & 5 & $0.43 \pm 0.11$ & 0.136 \\
\hline & CPP-ACP I & 5 & $0.24 \pm 0.08$ & \\
\hline \multirow[t]{3}{*}{ Aluminium } & Blood clam & 5 & $0.66 \pm 0.11$ & \\
\hline & Shrimp shell & 5 & $0.20 \pm 0.08$ & 0.565 \\
\hline & CPP-ACP I & 5 & $0.16 \pm 0.10$ & \\
\hline \multirow[t]{3}{*}{ Chlorine } & Blood clam & 5 & $0.55 \pm 0.32$ & \\
\hline & Shrimp shell & 5 & $0.53 \pm 0.11$ & 0.393 \\
\hline & CPP-ACP I & 5 & $0.57 \pm 0.11$ & \\
\hline \multirow[t]{3}{*}{ Potassium } & Blood clam & 5 & $1.05 \pm 0.14$ & \\
\hline & Shrimp shell & 5 & $0.88 \pm 0.07$ & 0.106 \\
\hline & CPP-ACP I & 5 & $0.87 \pm 0.03$ & \\
\hline
\end{tabular}

Independent t-test

\section{Conclusion}

This study proves that blood clam and shrimp shells have a composition similar to CCP-ACP so it is expected that blood clam (anadara granosa) paste and shrimp (litopanneus vannamei) paste have the effectiveness to become teeth remineralization material.

\section{Acknowledgment}

Authors are also grateful to the Dean of Faculty of Dentistry Hasanuddin University for their support and assistance.

\section{Conflict of Interest}

The author report no conflict of interest.

\section{References}

1. Ahmad I. Utilization of waste shells of blood (anadara granosa) as abrasive ingredients in toothpaste. J Galung Tropika 2017;6: 49-59.

2. Awang-Hazmi ABZ, Zuki MM, Nurdin A, et al. Mineral composition of the cokle (anadara granosa) shells of west coast of peninsular Malaysia and It's Potential as Biomaterial for Use in Bone Repair. J Anm Vet Adv 2005;6: 591-594.
3. Liam B, Philip O. Biofuels from microalgae a review of technologies for production, processing, and extractions of biofuels and co-products. Renew Sust Energ Rev 2010;14: 557-577.

4. Suptijah P, Agnes MZ, Daviyanti N. Characterization and biovailability of nano calcium vannamei shrimp shell. J Akuatika 2012;3: 63-73.

5. Thariq MRA, Fadli A, Rahmat A, et al. The development of the latest chitosan in various life applications: review. J Teknik Kimia 2016;5: 49-52.

6. Scheid RC, Weiss G. Woelfel's dental anatomy. 8th ed. Philadelhpia: Lippincott Williams \& Wilkins, a Wolters Kluwer business; 2012. p. 11

7. Nör JE. Buonocore memorial lecture: tooth regeneration in operative dentistry. Oper Dent 2006;31: 633-642.

8. Panigoro S, Pngemanan DHC, Juliatri. Levels of dissolved tooth calcium in soaking isotonic drinks. J e-GiGi (eG) 2015;3: 356-359.

9. Tongchan P, Prutipanlai, Niyomnas S, et al. Effect of calcium compund obtained from fish by product on calcium metabolism in rats. J Food AgInd 2009;2: 669-676.

10. Sobhy AElS, Gamal MH, Sameh EM. Biochemical and functional properties of Moringa oleifera leaves and their potential as a functional food. GARJAS 2015;4: 188-199.

11. Pipih S, Agoes MJ, Nani D. Characterization and bioavailability of shrimp nanocalcium vannamei (Litopenaeus Vannamei). J Akuatika 2012;3: 63-73.

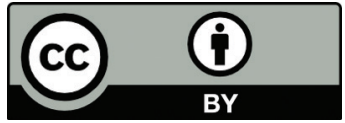

This work is licensed under a Creative Commons Attribution 